\title{
Simulated light regimes affect feeding and metabolism of Antarctic krill, Euphausia superba
}

\section{Mathias Teschke 1}

Scientific Division Biological Oceanography, Alfred Wegener Institute for Polar and Marine Research, Handelshafen 12, 27570 Bremerhaven, Germany

\section{So Kawaguchi}

Department of Environment and Heritage, Australian Antarctic Division, 203 Channel Highway, Kingston, Tasmania 7050, Australia

Bettina Meyer

Scientific Division Biological Oceanography, Alfred Wegener Institute for Polar and Marine Research, Handelshafen 12, 27570 Bremerhaven, Germany

\begin{abstract}
The effect of different light regimes on physiological parameters (feeding activity, oxygen consumption, and activity of the metabolic enzyme malate dehydrogenase [MDH]) of Antarctic krill, Euphausia superba, was studied over 12 weeks under laboratory conditions. Krill were exposed to light-cycle regimes of variable intensity to simulate Southern Ocean summer, autumn, and winter conditions, respectively, using: (1) continuous light (LL; 200 lux max), (2) 12-h light and 12-h darkness (LD 12:12; 50 lux max), and (3) continuous darkness (DD). In all experimental groups, the food concentration was kept at high levels $\left(\sim 800 \mu \mathrm{g} \mathrm{C} \mathrm{L}^{-1}\right)$. Krill exposed to LL and LD 12:12 showed an increase in all measured parameters over the experimental period. Physiological parameters of krill held under LD 12:12 showed a more consistent increase and remained below those of krill held under LL. No change was recorded for krill exposed to $\mathrm{DD}$; clearance rates and daily $\mathrm{C}$ rations did not respond to the high food availability, and oxygen consumption rates and MDH activity were significantly lower $(p<0.05)$ than those of krill exposed to summer light condition. Thus, changes in the environmental light regime have an important effect on physiological parameters of krill, such as feeding and metabolic rates, and may indicate an inherent overwinter adaptation strategy triggered by the Antarctic light regime.
\end{abstract}

Antarctic krill (Euphausia superba, hereafter krill) plays a central role in the Southern Ocean ecosystem and is the major trophic link between primary production and vertebrate top predators. Krill have adapted to a habitat with large seasonal changes in food availability, sea ice extent, day length, and light intensity. How krill survive the winter season when much of the Southern Ocean is covered by ice and phytoplankton concentration in the water column is extremely low was one of the key questions studied by the Southern Ocean Global Ocean Ecosystem Dynamics program (SO GLOBEC). Overwintering success of larval and adult krill is a decisive factor that influences

${ }^{1}$ Corresponding author (mteschke@awi-bremerhaven.de; tel.: +49(471)4831-1308).

\section{Acknowledgments}

This work was conducted at the Australian Antarctic Division (AAD) within the scope of the project "Experiments on Live Krill," and was part of the collaborative research agreement between the AAD and the Alfred Wegener Institute for Polar and Marine Research. The authors thank all krill scientists and staff of the AAD for their hospitality and support during our visit. We also thank R. King and T. Yoshida for their professional and friendly support in the aquarium. We thank R. Saborowski, A. Atkinson, and two anonymous reviewers for constructive comments on the manuscript.

This work was funded by the German Academic Exchange Service (DAAD). krill condition, recruitment, and population size (Siegel and Loeb 1995). Suggested survival mechanisms for adult krill fall into two categories: (1) nonfeeding strategies, and (2) conversion to alternative food sources. Nonfeeding strategies include the use of stored lipids (Hagen et al. 2001), reduction in metabolic rates (Kawaguchi et al. 1986; Quetin and Ross 1991; Torres et al. 1994), and shrinkage in size (Ikeda and Dixon 1982). Alternative food sources are ice biota (Marschall 1988), zooplankton (Huntley et al. 1994), and seafloor detritus (Kawaguchi et al. 1986).

The reduction in metabolic rates is regarded as one of the most effective energy-saving mechanisms for adult krill during winter (Quetin and Ross 1991). Meyer et al. (2002) found a significant reduction in activity of the metabolic key enzyme citrate synthase (CS) compared to summer values. Likewise, Cullen et al. (2003) found significant seasonal changes in CS activity and RNA: DNA (ribonucleic acid:deoxyribonucleic acid) ratio in krill. The decrease in metabolic rates seems to be the major physiological response of krill to the Antarctic winter, but the mechanisms that cause these reductions are still unknown.

A reduced metabolism of krill in winter may be caused simply and directly by the scarcity of food at this time of the year because food concentration ranges from $<0.1 \mu \mathrm{g}$ chlorophyll $a(\mathrm{Chl} a) \mathrm{L}^{-1}$ in winter to $>10 \mu \mathrm{g} \mathrm{Chl} a \mathrm{~L}^{-1}$ in summer. However, Atkinson et al. (2002) showed that this may not be the case, as respiration and clearance rates of krill in autumn were only one-third of those during 


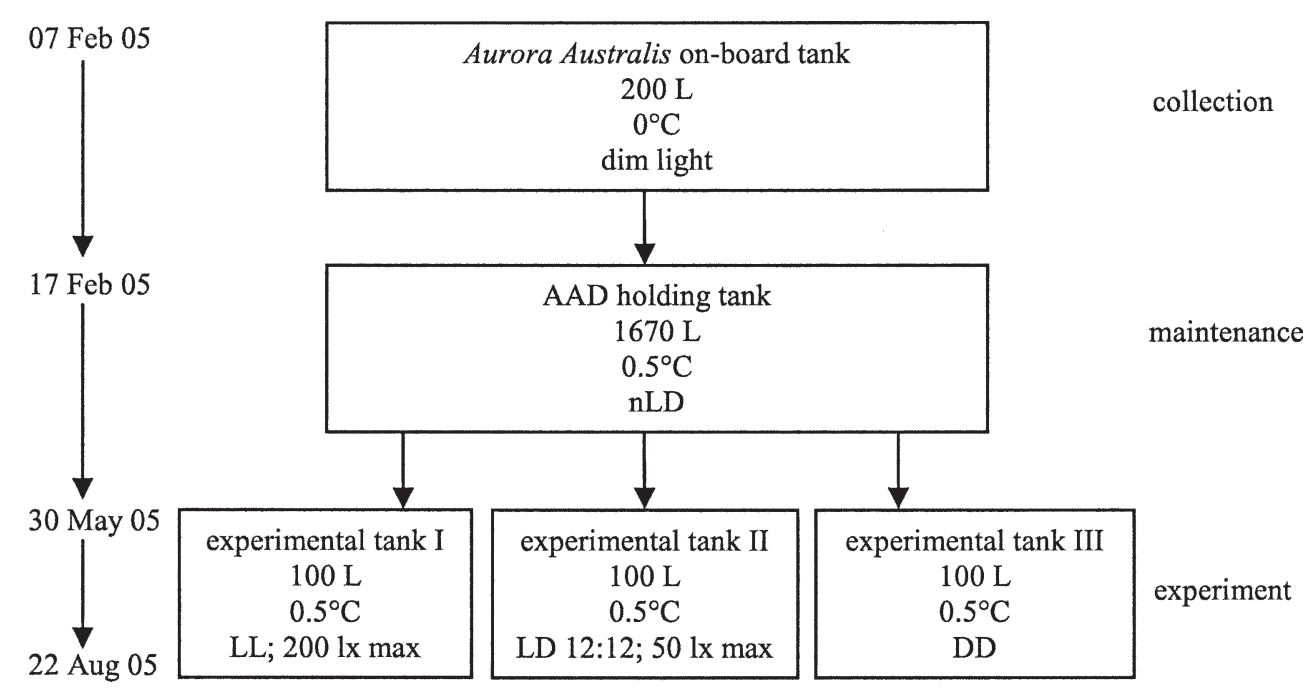

Fig. 1. Schematic representation of experimental krill maintenance from the day of collection (07 February 2005) to the end of the experiment (22 August 2005). Boxes describe different tanks and the corresponding water volume, water temperature, and light regime. LL; 200 lx max: continuous light with a maximum of 200-lux light intensity at the surface of the tank during midday. LD 12:12; 50 lx max: 12-h light and 12-h darkness with a maximum of 50-lux light intensity at the surface of the tank during midday. DD: continuous darkness. nLD: natural photoperiod (see Material and methods).

summer, and these did not increase even after $11 \mathrm{~d}$ exposure to abundant food. In the same experimental setup during summer, however, krill responded rapidly to high food concentrations (Atkinson and Snÿder 1997).

Seasonal differences in the metabolic status may be caused by an inherent annual rhythm that enables krill to adapt to the extreme seasonal changes in food availability between the Antarctic summer and winter and that is keyed to a strong seasonal cue in the Southern Ocean ecosystem. While temperature remains within a narrow annual range ( -2 to $2^{\circ} \mathrm{C}$ ), photoperiod and light intensity are environmental parameters with strong seasonality in the Southern Ocean. The Antarctic light regime in general may have important effects on physiological parameters of krill, such as feeding and metabolic rate. The photoperiod in the high Antarctic ranges from near-constant light in December to near-constant darkness in June, and it could represent a signal for the adjustment of the metabolic status of krill.

The aim of the present work was to study the effect of different light regimes on the metabolism and physiological status of krill. Changes in feeding rates, oxygen consumption, and the activity of the metabolic enzyme malate dehydrogenase (MDH) were recorded weekly during exposure to simulated summer, autumn/spring (hereafter autumn), and winter light conditions in the laboratory. This investigation provided further insights into the survival mechanisms of krill during winter, which are poorly known but are essential in understanding the population dynamic of this key species in the Southern Ocean.

Materials and methods

Sampling and maintaining krill in the laboratory-E. superba were caught by oblique hauls of a Rectangular
Midwater Trawl (RMT 8) in the upper $100 \mathrm{~m}$ of the water column in East Antarctica $\left(66^{\circ} 15^{\prime} \mathrm{S}, 74^{\circ} 45^{\prime} \mathrm{E}, 07\right.$ February 2005) during the voyage V3 04/05 with RSV Aurora Australis. Immediately after capture, krill were transferred into 200-L tanks located in a constant-temperature room at $0^{\circ} \mathrm{C}$ and dim light (Fig. 1). Each day, 50\% of the water was exchanged with fresh prechilled seawater to ensure a continual turnover of food and nutrients. Twice a day, dead animals and moults were removed from the tanks.

After arriving in Hobart, Tasmania (17 February 2005), krill were delivered directly to the Australian Antarctic Division (AAD) aquarium and kept in a 1,670-L holding tank (Fig. 1). The holding tank was connected to a 5,000-L chilled seawater recirculation system. The seawater was maintained at $0.5^{\circ} \mathrm{C}$ and was recirculated every hour through an array of filtration devices. Water quality was monitored continuously. Lighting was provided by fluorescent tubes. A personal computer (PC) controlled-timer system was used to set a natural photoperiod (nLD) corresponding to that for the Southern Ocean $\left(66^{\circ} \mathrm{S}\right.$ at 30 $\mathrm{m}$ depth). Presupposing continuous light and a maximum of 100-lux light intensity at the surface of the tank (assuming 1\% light penetration to 30-m depth) during summer midday (December), a sinusoidal annual cycle with monthly variations of photoperiod and daily variation of light intensity was calculated. At the beginning of each month, a new photoperiod was simulated by adjusting the timer system.

One thousand, five hundred krill were fed daily with the following algae at the final concentrations of $1.5 \times$ $10^{4}$ cells $\mathrm{mL}^{-1}$ of the pennate diatom Phaeodactylum tricornutum, $2.2 \times 10^{4}$ cells $\mathrm{mL}^{-1}$ of the flagellate Isochrysis sp., and $1.6 \times 10^{4}$ cells $\mathrm{mL}^{-1}$ of the flagellate Pavlova sp. (Reed Mariculture). Water flow in the tank was 
closed (for $8 \mathrm{~h}$ ) to enable krill to feed on the algal mixture. These algae had been used successfully in several experimental trials at the AAD prior to this study (King et al. 2003), and they guarantee good condition of krill in longterm laboratory experiments with low mortality and high feeding rates.

Experimental design-Before starting the light experiments on 30 May 2005, feeding activity in the holding tank was measured (Fig. 1). Additionally, 10 individuals were taken from the holding tank to measure oxygen uptake rates (4 krill) and MDH activity (6 krill). The body length and the digestive gland length were measured in all subsampled krill. These data were used as time zero $\left(t_{0}\right)$ for all experiments.

From the holding tank, 450 krill of mixed sex (mean length $\sim 38 \mathrm{~mm}$ ) were separated into three cylindrical 100$\mathrm{L}$ tanks (150 krill each) situated within one 1,000-L rectangular container. This system was connected to a 5,000-L chilled seawater recirculation system. The water was maintained at $0.5^{\circ} \mathrm{C}$. All tanks within the container had separate water in- and outflow. The chilled water was simultaneously pumped into the container and into each experimental tank. All tanks drained back to the container, where the water entered into an array of filtration devices. After filtration, the water was pumped back to the container and tanks. The design of the experimental recirculating facility guaranteed identical water quality and temperature for every experimental stock throughout the study.

Each tank was covered with a black lightproof plastic container with a sliding door at the front side to create a separate light compartment. Lighting was provided by fluorescent tubes (Osram L18W/640 Cool White) covered with a filter film around the outside (ARRI, Marine Blue 131). Photoperiod and light intensity were controlled by a PC-controlled timer system. The three tanks were exposed to one of the following light regimes to simulate Southern Ocean summer, autumn, and winter conditions, respectively: experimental tank (1) summer: continuous light (LL) with a maximum of 200-lux light intensity at the surface of the tank during midday (assuming 20,000 lux at summer sea surface and 1\% light at 30-m depth); experimental tank (2) autumn: 12-h light and 12-h darkness (LD 12:12) with a maximum of 50-lux light intensity at the surface of the tank during midday; and experimental tank (3) winter: continuous darkness (DD) (Fig. 2).

All three experimental stocks were fed daily with the same algae used in the holding tank at final densities of 3.8 $\times 10^{4}$ cells $\mathrm{mL}^{-1}$ for $P$. tricornutum, $9.2 \times 10^{4}$ cells $\mathrm{mL}^{-1}$ for Isochrysis sp., and $6.6 \times 10^{4}$ cells $\mathrm{mL}^{-1}$ for Pavlova sp. The tanks were checked daily for mortality and moulting. Moults were collected and preserved in $10 \%$ formalin solution.

Every week, feeding activity was determined in the experimental tanks by measuring clearance rate and daily carbon ration. Ten krill were subsampled from each tank to measure oxygen uptake rates (4 krill) and MDH activity (6 krill). Body length and digestive gland length were

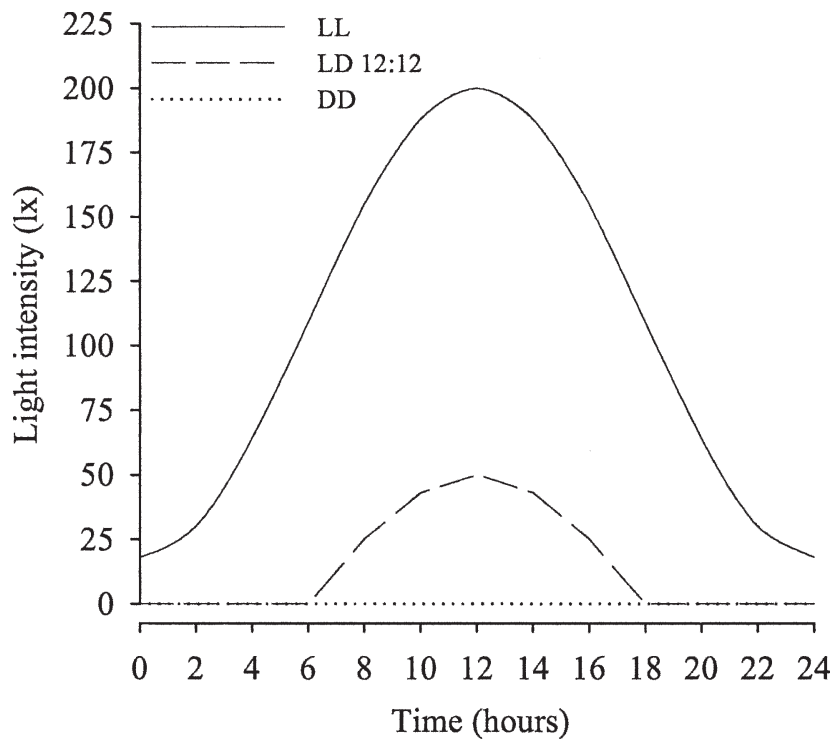

Fig. 2. Schematic representation of 24-h light regimes in the experimental tanks. LL: continuous light. LD 12:12: $12 \mathrm{~h}$ of light and $12 \mathrm{~h}$ of darkness. DD: continuous darkness.

measured in all subsampled krill. The krill were then stored immediately at $-80^{\circ} \mathrm{C}$ for further analyses.

Measurement of feeding activity-Shortly before the algae diet was added into each tank, water flow in the tank was stopped for $5 \mathrm{~h}$ to enable krill to feed on the algae mixture. Immediately after addition and mixing of the algae diet, three replicate subsamples were siphoned to 250$\mathrm{mL}$ bottles for Chl $a$ analysis from each tank to measure the initial concentration of the food. The bottles were incubated in the corresponding tank for the duration that the water flow was stopped in the tanks $(5 \mathrm{~h})$. After the incubation time, the water from each tank was gently mixed, and three replicate subsamples were transferred through silicon tubing to $250-\mathrm{mL}$ bottles to measure the final concentration in the tanks. Subsamples of $50 \mathrm{~mL}$ from each bottle were filtered onto Whatman GF/F filters, which were incubated overnight in $25 \mathrm{~mL}$ of $90 \%$ aqueous acetone at $4{ }^{\circ} \mathrm{C}$ in the dark and centrifuged $(700 \mathrm{~g})$ for 3 min. The supernatant was used to measure $\mathrm{Chl} a$ with a Turner 10-005R fluorometer.

Clearance rates on the total phytoplankton biomass in each tank were calculated by the formula:

$$
F=\ln \left(C_{\mathrm{c}} / C_{\mathrm{k}}\right) V / m_{\mathrm{k}} t,
$$

where $F$ is the clearance rate $\left(\mathrm{mL} \mathrm{mg}^{-1}\right.$ body $\left.\mathrm{C} \mathrm{h}^{-1}\right), C_{\mathrm{c}}$ is the initial concentration in the tanks, $C_{\mathrm{k}}$ is the final concentration in the tanks, $V$ is the volume of the tank $(\mathrm{mL}), m_{\mathrm{k}}$ is the body mass $(\mathrm{mg} \mathrm{C})$ of the animals, and $t$ is the experimental duration (h).

Ingestion rates were calculated as the product of the clearance rate of the phytoplankton biomass $\left(\mathrm{mL} \mathrm{mg}^{-1}\right.$ body $\left.\mathrm{C} \mathrm{h}^{-1}\right)$ and its initial $\mathrm{C}$ concentration $\left(\mathrm{mg} \mathrm{C} \mathrm{mL}^{-1}\right)$ and then expressed as a daily $\mathrm{C}$ ration (\% body $\mathrm{C} \mathrm{d}^{-1}$ ) 
under the assumption that the krill feeding rates reflected the daily average rate. The measured Chl $a$ concentrations were converted to $\mathrm{C}$ equivalents using a $\mathrm{C}: \mathrm{Chl} a$ ratio of 50 (Meyer et al. 2003).

Measurements of body length and size of digestive glandThe body length of subsampled krill was measured from the anterior tip of the rostrum to the posterior end of the uropods, excluding their terminal setae. The digestive gland of subsampled krill was measured through the carapace along its longest axis (Nicol et al. 2004). The length of the digestive gland is expressed as percent of body length.

Respiration measurements - Oxygen uptake measurements were run in filtered seawater $(0.1-\mu \mathrm{m}$ pore size). From each tank, four krill were used and incubated individually in 1.5-L bottles. One bottle of the same volume without krill was used as control for each tank. The krill were rinsed and added to the incubation bottles, which were then topped-up and sealed with parafilm and incubated for $24 \mathrm{~h}$ in the experimental tanks. Subsampling at the end of the incubation time was done by inserting a glass tube and siphoning the mixed contents of each bottle into $50-\mathrm{mL}$ Winkler bottles, according to Atkinson et al. (2002). Three replicates were filled for each experimental bottle. Oxygen concentrations were measured after immediate fixation for Winkler titrations as described in Meyer et al. (2002), using a 702 SM Titrino (Metrohm). The decrease in oxygen concentration for all experiments was $<20 \%$.

$M D H$ activity-MDH activity (E.C. 1.1.1.37) was measured in the fifth abdominal segment, which was dissected on ice. The segment was placed into preweighed microtubes, and fresh weight (fw) was analyzed by using a microbalance. Extracts of segment tissues were prepared

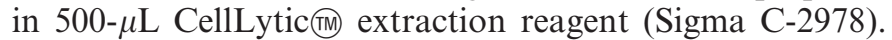
Homogenization was performed on ice with a Bio-Vortexer IIII) for $10 \mathrm{~s}$, followed by sonication with an ultrasonic cell disrupter using one burst of $10 \mathrm{~s}$. The homogenates were incubated for $15 \mathrm{~min}$ at $20^{\circ} \mathrm{C}$ on a shaker and then centrifuged for $15 \mathrm{~min}$ at $14,000 \mathrm{rpm}$ and $4^{\circ} \mathrm{C}$. The supernatants were transferred into new reaction cups and stored at $-80^{\circ} \mathrm{C}$ until analysis.

$\mathrm{MDH}$ activity was determined as follows: $810 \mu \mathrm{L}$ of reaction buffer $\left(0.1 \mathrm{~mol} \mathrm{~L}^{-1}\right.$ potassium phosphate, $\mathrm{pH}$ 7.0), $30 \mu \mathrm{L}$ of nicotinamide adenine dinucleotide, reduced form (NADH, $7 \mathrm{mmol} \mathrm{L}^{-1}$ in distilled water), and $30 \mu \mathrm{L}$ of sample were mixed in a semimicrocuvette. After $5 \mathrm{~min}$ of pre-incubation at $30^{\circ} \mathrm{C}$, the reaction was initiated by adding $30 \mu \mathrm{L}$ of oxaloacetate $\left(12 \mathrm{mmol} \mathrm{L}^{-1}\right.$ in distilled water). The change in absorbance at $340 \mathrm{~nm}$ was recorded for another $3 \mathrm{~min}$. The activity was expressed as $\mathrm{U} \mathrm{g}_{\mathrm{fw}}{ }^{-1}\left(=\mu \mathrm{mol} \mathrm{min}{ }^{-1} \mathrm{~g}_{\mathrm{fw}^{-1}}{ }^{-1}\right)$ using the extinction coefficient $\varepsilon_{340}=6.22 \mathrm{~L} \mathrm{mmol}^{-1} \mathrm{~cm}^{-1}$.

Statistical analysis-All tests were performed with the computer program SigmaStat 3.00 (SPSS) and the STATISTICA software package 6.1 (StatSoft). While feeding activity in the experimental tanks was measured on the basis of single treatment levels, individual krill were treated as replicates in all other analyses. For analysis of differences in feeding activity among the different light regimes, we explored a relationship between clearance rate and daily carbon ration of krill and time by use of linear regressions. We tested the effect of the different light regimes on feeding activity by analyzing the differences of slopes and intercepts of the regression lines. Equality of slopes was tested using an F-test, and a Tukey test was performed to detect differences among slopes. The effects of time and light regime on digestive gland length, oxygen demand, and MDH activity were analyzed using a two-way analysis of covariance (ANCOVA) using body length of krill as a covariate, in order to separate the effect of krill size from treatment effect. A Holm-Sidak post-hoc test was used to perform pairwise multiple comparisons to detect temporal significant differences among the light regimes. Data on oxygen demand and MDH activity, initially not normally distributed, were square root transformed and were finally normally distributed. The significance level for all tests was set at $p<0.05$. Data were expressed as mean \pm standard deviation (SD).

\section{Results}

Feeding activity - The greatest increase in clearance rate was observed in krill exposed to LL followed by krill exposed to LD 12:12 (Fig. 3a,b). Clearance rate ranged from 1.8 to $7.7 \mathrm{~mL} \mathrm{mg}^{-1}$ body $\mathrm{C} \mathrm{h}^{-1}$ and 1.8 to $4.6 \mathrm{~mL} \mathrm{mg} \mathrm{mg}^{-1}$ body $\mathrm{C} \mathrm{h}^{-1}$ from the beginning $\left(t_{0}\right.$ group) until the end of the experiment (12 weeks). Krill exposed to DD showed no increase in clearance rate during the experimental period. Values ranged between 1.1 and $2.5 \mathrm{~mL} \mathrm{mg}^{-1}$ body $\mathrm{C} \mathrm{h}^{-1}$ and were only $12 \%$ of clearance rate of krill exposed to LL at the end of the study (Fig. 3c).

Krill held under LL showed a strong increase in daily carbon ration, from $1.4 \%$ at $t_{0}$ to $26.3 \%$ body $\mathrm{C} \mathrm{d}^{-1}$ after 12 weeks with a maximum of $41.1 \%$ body $\mathrm{C} \mathrm{d}^{-1}$ in week 11 (Fig. 4a). In krill exposed to LD 12:12, daily carbon ration increased during the first three weeks from $1.4 \%$ body $\mathrm{C}$ $\mathrm{d}^{-1}$ at $t_{0}$ to $9.1 \%$ body $\mathrm{C} \mathrm{d}^{-1}$, remained constant until week 9 , and increased to $16.1 \%$ body $\mathrm{C} \mathrm{d}^{-1}$ at the end of the experiment (Fig. 4b). Daily carbon ration of krill held under DD ranged from $1.4 \%$ to $9.8 \%$ body $\mathrm{C} \mathrm{d}^{-1}$, with no distinct changes over the experimental period. At the end of the study, daily carbon ration of krill held under DD was only $12 \%$ of that of krill exposed to LL (Fig. 4c).

The analysis of regression lines of temporal changes in clearance rate and daily carbon ration among the different light regimes revealed significant differences of slopes among the different regressions, indicating a light regime effect.

Krill from the different light regimes showed significant temporal differences in the length of their digestive glands $(p<0.05 ;$ Fig. 5). The digestive gland length of krill from all three experimental tanks decreased within the first two weeks. However, through the remainder of the experiment a distinct increase in digestive gland length of krill held under LL and LD 12:12 from $9.8 \% \pm 1.3 \%$ to $14.5 \% \pm$ 

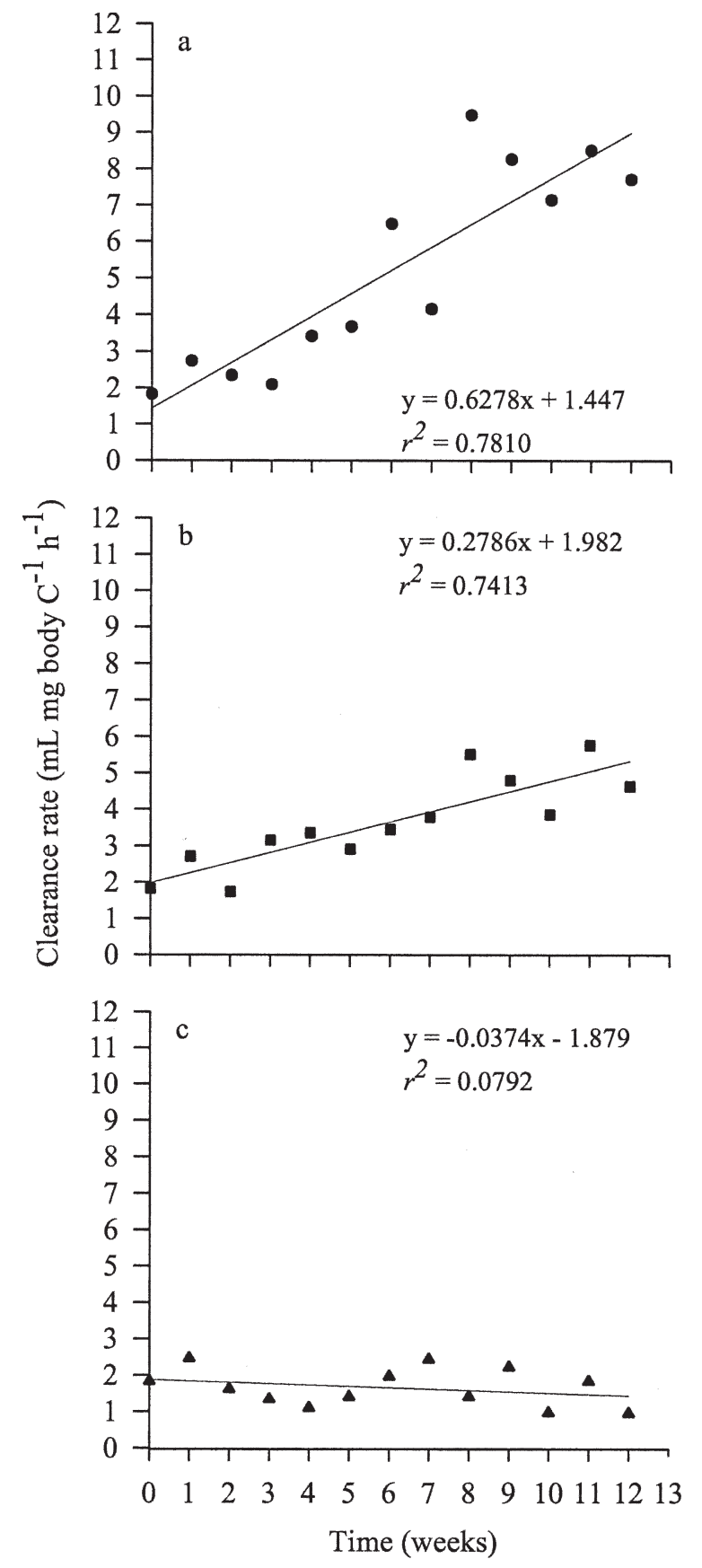

Fig. 3. Changes in clearance rates of Antarctic krill exposed to (a) continuous light (LL), (b) $12 \mathrm{~h}$ of light and $12 \mathrm{~h}$ of darkness (LD 12:12), and (c) continuous darkness (DD) over an experimental period of 12 weeks. Values represent the mean of 3 replicate subsamples. Slopes among regression are significantly different $\left(F_{0.05,2,33}=23.74, p<0.0001\right)$. LL is significantly different from LD $12: 12\left(q_{0.05,33,2}=4.41\right)$ and $\operatorname{DD}\left(q_{0.05,33,2}=\right.$ 8.76). LD $12: 12$ is significantly different from $\mathrm{DD}\left(q_{0,05,33,2}\right.$ $=7.09$ ).

$0.7 \%$ body length and from $9.9 \% \pm 0.7 \%$ to $13.3 \% \pm 1.0 \%$ body length was recorded, respectively. The digestive gland length of krill exposed to DD remained mainly constant, ranging between $8.2 \% \pm 1.2 \%$ and $9.6 \% \pm 1.1 \%$ body length. After five weeks, and through the end of the
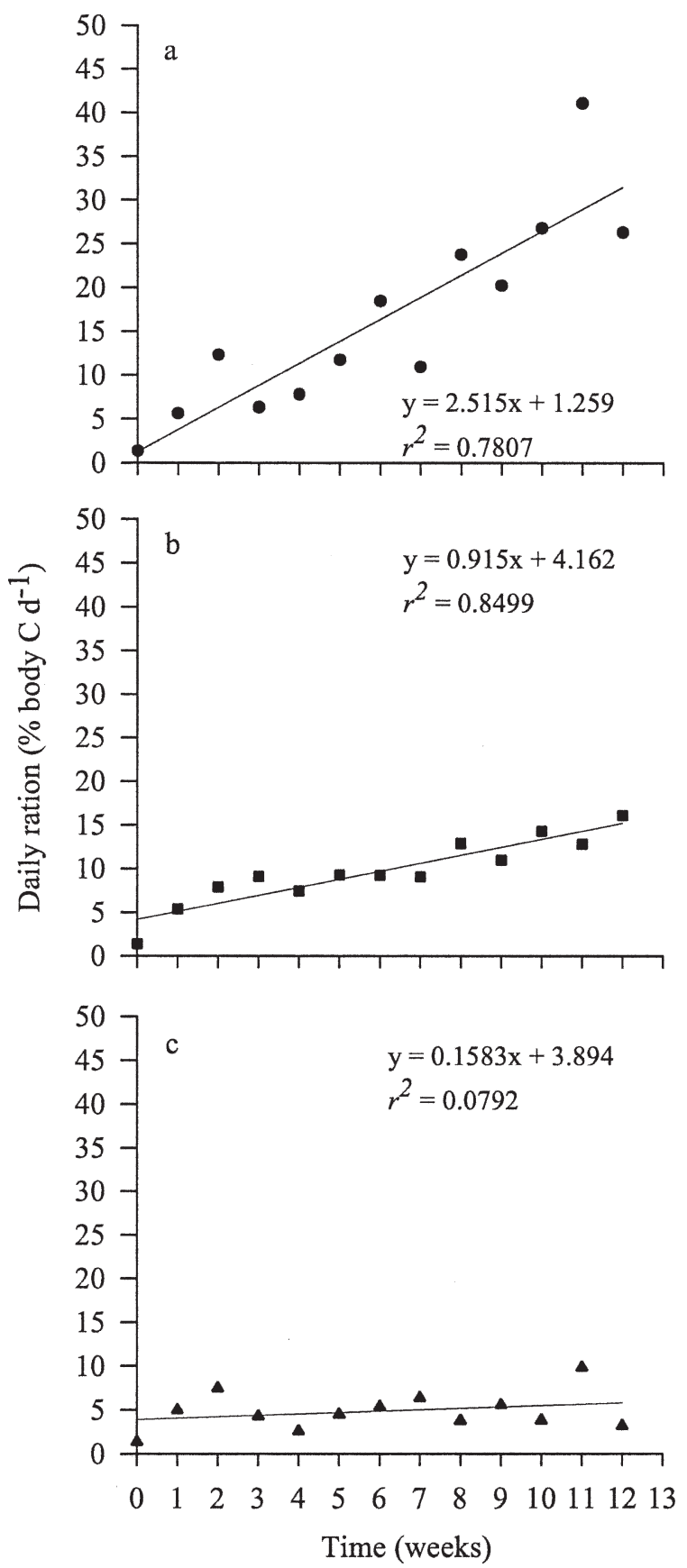

Fig. 4. Changes in daily carbon rations of Antarctic krill exposed to (a) continuous light (LL), (b) $12 \mathrm{~h}$ of light and $12 \mathrm{~h}$ of darkness (LD 12:12), and (c) continuous darkness (DD) over an experimental period of 12 weeks. Values represent the mean of three replicate subsamples. Slopes among regression are significantly different $\left(F_{0.05,2,33}=21.53, p<0.0001\right)$. LL is significantly different from $\operatorname{LD} 12: 12\left(q_{0.05,33,2}=5.39\right)$ and $\operatorname{DD}\left(q_{0.05,33,2}=\right.$ 7.69). LD $12: 12$ is significantly different from $\mathrm{DD}\left(q_{0.05,33,2}\right.$ $=5.38)$.

experiment, digestive gland length of krill held under continuous darkness was significantly lower $(p<0.05)$ than that of krill exposed to LL and LD 12:12. At the end of the study, digestive gland length of krill held under DD was $60 \%$ of that of krill exposed to LL. 


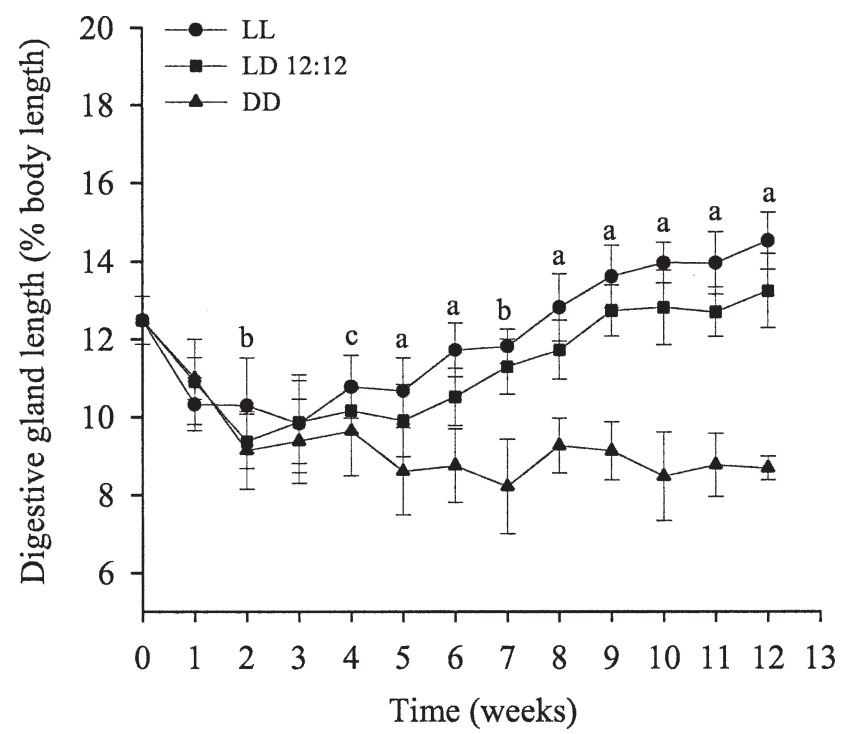

Fig. 5. Changes in digestive gland length (expressed as percentage body length) of Antarctic krill exposed to continuous light (LL), $12 \mathrm{~h}$ of light and $12 \mathrm{~h}$ of darkness (LD 12:12), and continuous darkness (DD) over an experimental period of 12 weeks. Letters indicate significant differences $(p<0.05)$ : (a) LL is significantly different from LD $12: 12$ and DD, LD $12: 12$ is significantly different from DD; (b) LL is significantly different from DD, DD is significantly different from LD 12:12; and (c) LL is significantly different from DD. Vertical bars indicate \pm SD $(n=10)$.

Respiration rates-Krill exposed to the different light regimes showed significant temporal differences in their mean oxygen uptake rates $(p<0.05$; Fig. 6$)$. Respiration rates dropped within the first two weeks in all experimental groups. Krill held under LL and LD 12:12 showed a clear increase in their oxygen uptake rates, while respiration rates of krill exposed to DD remained mainly constant, ranging between $22.0 \pm 3.1$ and $30.0 \pm 8.4 \mu \mathrm{L} \mathrm{O}$ individual (ind) $)^{-1} \mathrm{~h}^{-1}$. The respiration rates of krill held under LL ranged between $22.9 \pm 8.8$ and $53.7 \pm 12.9 \mu \mathrm{L}$ $\mathrm{O}_{2}$ ind $^{-1} \mathrm{~h}^{-1}$ after week 2 until the end of the experiment. In the same experimental period, values of krill held under LD $12: 12$ were between $26.6 \pm 7.3$ and $44.7 \pm 11.1 \mu \mathrm{L} \mathrm{O}_{2}$ ind $^{-1} \mathrm{~h}^{-1}$. After 8 weeks, and until the end of the experiment, respiration rates of krill exposed to DD were significantly lower $(p<0.05)$ than the rates of krill exposed to LL and LD $12: 12$, and were only $61 \%$ of those of krill exposed to LL after week 12.

$M D H$ activity-Krill from the different experimental tanks showed no significant temporal differences in their MDH activity until week $10(p>0.05$; Fig. 7$)$. MDH activity of krill from all experimental tanks ranged between $222.8 \pm 32.3$ and $291.2 \pm 83.5 \mathrm{U} \mathrm{g}_{\mathrm{fw}^{-1}}{ }^{-1}$ in the first 6 weeks. From that time on, MDH activity in krill held under LL increased to a maximum of $369.3 \pm 78.0 \mathrm{U} \mathrm{g}_{\mathrm{fw}}{ }^{-1}$ in week 11. In krill held under LD 12:12, MDH activity was highest after 9 weeks $\left(321.1 \pm 93.6 \mathrm{U} \mathrm{g}_{\mathrm{fw}}{ }^{-1}\right)$. In contrast, after 10 weeks, krill exposed to DD showed their lowest

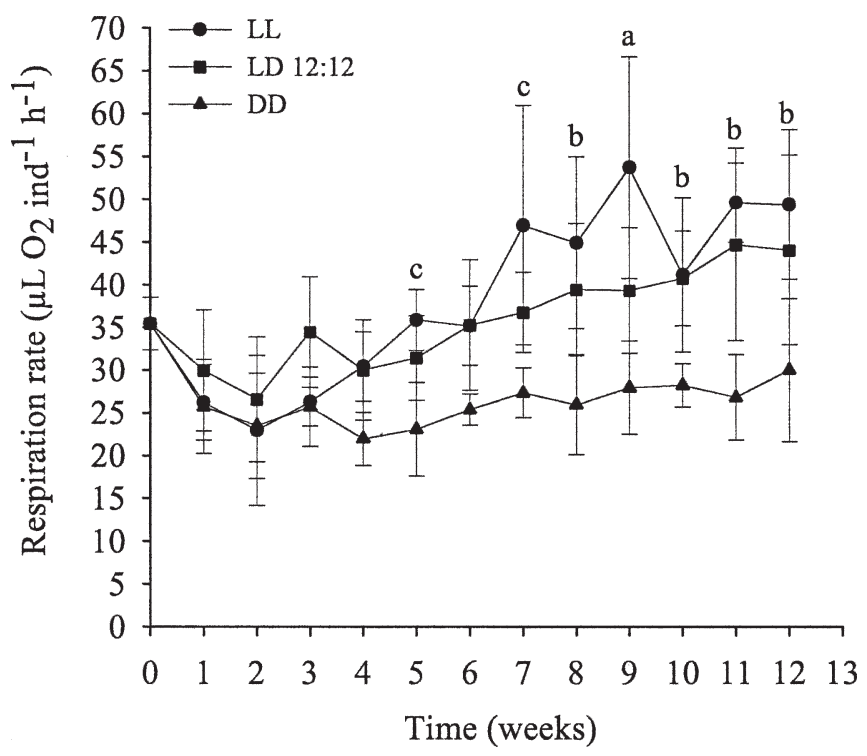

Fig. 6. Changes in respiration rate of Antarctic krill exposed to continuous light (LL), $12 \mathrm{~h}$ of light and $12 \mathrm{~h}$ of darkness (LD $12: 12$ ), and continuous darkness (DD) over an experimental period of 12 weeks. Letters indicate significant differences $(p<$ 0.05): (a) LL is significantly different from LD 12:12 and DD, LD $12: 12$ is significantly different from DD; (b) LL is significantly different from DD, DD is significantly different from LD 12:12; and (c) LL is significantly different from DD. Vertical bars indicate $\pm \mathrm{SD}(n=4)$.

MDH activity $\left(219.3 \pm 27.4 \mathrm{U} \mathrm{g}_{\mathrm{fw}}{ }^{-1}\right)$, followed by a slight increase to $244.2 \pm 41.4 \mathrm{U} \mathrm{g}_{\mathrm{fw}^{-1}}{ }^{-1}$ at the end of the experiment, which was $74 \%$ of the MDH activity of krill exposed to LL.

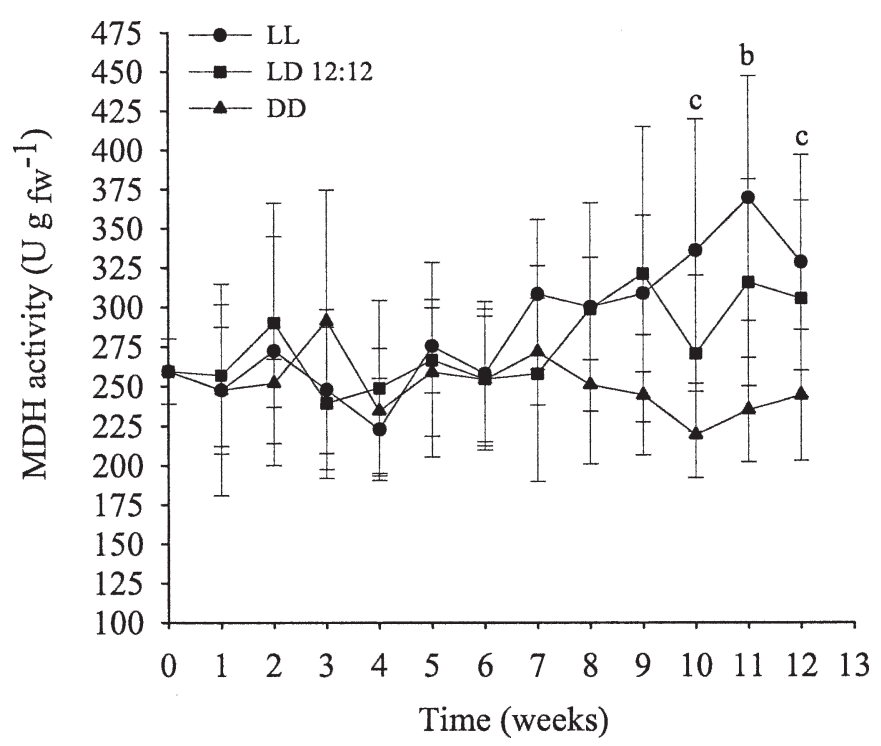

Fig. 7. Changes in MDH activity of Antarctic krill exposed to continuous light (LL), $12 \mathrm{~h}$ of light and $12 \mathrm{~h}$ of darkness (LD $12: 12$ ), and continuous darkness (DD) over an experimental period of 12 weeks. Letters indicate significant differences $(p<$ 0.05): (b) LL is significantly different from $\mathrm{DD}, \mathrm{DD}$ is significantly different from LD 12:12; and (c) LL is significantly different from DD. Vertical bars indicate \pm SD $(n=6)$. 
The analysis of covariance of digestive gland length, oxygen demand, and MDH activity using body length of krill as a covariate showed a significant effect and significant interaction of time and light regime for all three dependent variables (time, light regime, time $\times$ light regime; $p<0.001$ ), indicating a light regime effect. While there was no significant effect of body length on digestive gland length of krill at any time within any light regime, body length of krill had a significant effect on respiration rates and $\mathrm{MDH}$ activity (body length, $p<0.001$ ). However, analysis of covariance of oxygen demand and MDH activity showed no significant interactions among body length and time and light regime, indicating that the effect of light regime did not depend on the value of body length.

\section{Discussion}

Our work has shown the influence of different simulated light regimes on physiological function of E. superba for the first time. Although all experimental groups received sufficient food, differences in physiological status related to different light regimes were observed. The results indicate an important effect of the different experimental light regimes, which simulated Antarctic summer, autumn, and winter, and this will be discussed in relation to suggested overwintering mechanisms for adult krill.

The mechanisms for overwintering in krill are still poorly known, and this topic is characterized by much speculation, few data, and some controversy. Suggested survival mechanisms fall into two categories: nonfeeding strategies (reduction in metabolic rates, starvation, and use of lipid reserves, shrinkage), and conversion to alternative food sources (ice biota, zooplankton, seafloor detritus).

Quetin and Ross (1991) suggested a reduction in metabolic rate as the most important energy-saving mechanism for adult krill in winter. Compared to summer values, several other studies demonstrated reduced metabolic rates and/or low or zero feeding rates of krill at the onset of winter (Atkinson et al. 2002; Meyer et al. 2002) and during winter (Morris and Priddle 1984; Quetin and Ross 1991; Cullen et al. 2003). Torres et al. (1994) suggested a "compromise" overwinter strategy for krill with reduced metabolism and feeding activity that was also found by Atkinson et al. (2002) during an autumn study.

Overall, it remains unclear whether the reduced metabolic rates are caused simply by low food supply and feeding rates in winter, or whether there is a more fundamental seasonal transition in the animal's physiology, irrespective of ambient food levels. Evidence for the latter was demonstrated by Atkinson et al. (2002). Clearance rates of juvenile and adult krill during an autumn study were $<30 \%$ of summer rates and failed to respond even when acclimated to high food concentrations for $11 \mathrm{~d}$.

Our results show that changes in feeding and metabolic activity among the different light regimes are not primarily the result of short-term acclimation to high food concentration. In this study, we exposed krill to simulated Antarctic summer, autumn, and winter light regimes, while the food concentration was kept at high levels $(\sim 800 \mu \mathrm{g} \mathrm{C}$
$\mathrm{L}^{-1}$ ) in all experimental groups. Hamner et al. (1983) found that feeding behavior of krill is affected by several chemical phytoplankton compounds. The authors suggested a chemically induced feeding reaction as an advantageous mechanism to improve food exploitation during the dark period. If this had been the case in our experiments, we would have seen similar responses in all three groups. Clearance rates and daily rations of krill held under DD failed to respond to high food concentrations, and by the end of the experiment, they were only $12 \%$ of those of krill exposed to LL. In addition, no increase in size of the digestive gland was recorded. The size of the digestive gland can provide further information on how intensively the krill have been feeding in the previous days and weeks (Nicol et al. 2004).

A similar trend was shown in oxygen consumption rates and MDH activity. These parameters give indications of metabolic changes at overall and molecular level. $\mathrm{MDH}$ is a metabolic enzyme that catalyzes reactions in the citric acid cycle and energy metabolism. Activity of MDH shows high positive correlation with oxygen consumption rates and is considered as an effective molecular proxy for metabolic rate (Donnelly et al. 2004). Oxygen consumption rates were determined to asses the overall metabolic response to the simulated light regimes.

Respiration rates and digestive gland length of krill from all three experimental tanks dropped within the first two weeks of the experimental period. Krill might have undergone an initial shock caused by the change of environmental conditions between the holding tank and the experimental tanks, which resulted in a decrease of these two parameters.

We demonstrated that changes in feeding activity and metabolic rates in krill are not simply the result of food supply, but it remains uncertain whether oxygen uptake rates and MDH activity are the result of changes in feeding activity or whether it is the other way around, with feeding rates reflecting changes in metabolic rate. Ikeda and Dixon (1984) suggested that the specific dynamic action (SDA), which is defined as the increase of metabolic activity following ingestion of food, is the major cause of enhanced oxygen uptake of krill. Another explanation could be that increased feeding activity causes enhanced locomotor activity followed by higher oxygen uptake rates and $\mathrm{MDH}$ activities. Therefore, the increase in metabolic rates could be interpreted as reflection of enhanced feeding rates. Controversially, during a field study, Kawaguchi et al. (1986) noted an increase in oxygen consumption of krill correlating with an increase in solar radiation in spite of poor food conditions. This finding would favor the hypothesis that increased feeding activity is caused by enhanced metabolic activity.

Our results indicate that feeding and metabolic activity of krill were affected by the different simulated light regimes. Values of krill held under LD 12:12, and thus exposed to half of day length and $25 \%$ of light intensity compared to LL, showed a more consistent increase and remained below values of krill held under LL. Krill exposed to DD showed no evident change of parameters. In addition, the digestive gland length of krill exposed to 
DD at the end of the experiment was still smaller than that of krill at time zero $\left(t_{0}\right)$. After the initial decrease of digestive gland length of krill from all three experimental tanks, the gland length of krill exposed to DD should have reached at least a similar size to that of krill at time zero $\left(t_{0}\right)$, which was not the case.

The effects of light on feeding activity and metabolic rate of E. superba are unknown. Hirano et al. (2003) demonstrated that maturation and spawning of krill were induced by controlled photoperiod changes during a laboratory study. This indicates that the photoperiod as an environmental factor can influence physiological processes in krill. In general, studies demonstrating the influence of light on feeding rates and metabolism in crustaceans are rare. Fanjul-Moles et al. (1998) demonstrated the effect of light on the neural and endocrine structures responsible for the control of behavior and metabolic functions of crayfish during exposure to different photoperiods and light intensities. However, several studies have indicated the relevance of light duration and intensity on diverse other biological processes in crustaceans (Gardner and Maguire 1998; Otero et al. 1998; Hoang et al. 2003). Overall, photoperiod and light intensity have been shown to affect physiological and behavioral parameters in a range of other aquatic animals, including fish (Biswas et al. 2005), molluscs (Duinker et al. 1999), and turtles (Southwood et al. 2003), suggesting the importance of these environmental parameters.

In our study, krill were exposed to different simulated environmental light conditions (summer, autumn, winter). In order to simulate the Antarctic summer and autumn conditions most accurately, we adjusted the light regimes to different photoperiods and light intensities (see Materials and methods, Fig. 2). Consequently, it remains unclear whether the changes in the physiological status of krill were triggered directly by changes of a primary factor, such as light intensity, or triggered by changes of an environmental signal, such as photoperiod. In addition, differences in the physiological status of krill also could have been caused by an internal clock, independent of direct control. In this case, different simulated light regimes may have acted as a synchronizer to adapt the internal clock to the experimental condition. The results from this study, in particular, changes of feeding activity among the different light regimes, showed a relatively rapid and straight response to different treatments. This may indicate that changes in the physiological status of krill were triggered directly by the simulated light conditions, rather than by an internal clock mechanism, which would imply a more prolonged response. However, to study the response mechanism to differences in light conditions, further studies dealing with detailed characterizations on the effects of light are required.

Changes in the light regime might be transmitted via differences in melatonin secretion in krill, which then influence its physiology; the indoleamine melatonin is suspected to act as a transducer of photoperiodic information (Reiter 1991). The presence of melatonin in crustaceans is well documented, and its related enzyme, $\mathrm{N}$ acetyltransferase (NAT), is present within the visual system of several species. Recent studies have indicated variable patterns of melatonin production and a variable influence of melatonin in modulating biological circadian and seasonal rhythms in crustaceans (Vivien-Roels and Pévet 1993; Balzer et al. 1997; Tilden et al. 2003). To date, the production of melatonin and its influence on physiological mechanisms and behavior in Antarctic krill E. superba are unknown.

Preliminary melatonin determinations in eyestalks and hemolymph of Antarctic krill have shown concentrations of $\sim 1 \mathrm{pg} \mathrm{mg}_{\mathrm{fw}^{-1}}{ }^{-1}$ and $\sim 0.2 \mathrm{pg} \mu \mathrm{L}^{-1}$ immunoreactive melatonin, respectively (unpubl. data). In this study, it remains an open question whether melatonin in krill was involved in initiating physiological changes during the experiment, but the results indicate the presence of a hormone that is involved in conveying photoperiodic information and thus underline the proposed effect of light on the physiology of $E$. superba. Further studies dealing with the nature of this hormone and its mode of action are suggested.

Seasonal changes of the physiological status of $E$. superba have been reported at different times and places. It seems that the decrease in metabolic rates is the major physiological response of krill to the Antarctic winter. The results from this study suggest that seasonal changes in the physiological status of adult krill are more the result of fundamental seasonal adaptations in animal physiology and behavior irrespective of ambient food levels. The study underlines the important effect of the Antarctic light cycle on physiological parameters of krill such as feeding and metabolic rates. This may indicate an inherent adaptational overwinter strategy triggered by the Antarctic light regime.

\section{References}

Atrinson, A., B. Meyer, U. Bathmann, D. Stübing, W. Hagen, AND K. Schmidt. 2002. Feeding and energy budget of Antarctic krill Euphausia superba at the onset of winter. II. Juveniles and adults. Limnol. Oceanogr. 47: 953-966.

, AND R. SNŸDER. 1997. Krill-copepod interactions at South Georgia, Antarctica, I. Omnivory by Euphausia superba. Mar. Ecol. Prog. Ser. 160: 63-76.

Balzer, I., I. R. Espinola, and B. Fuentes-Pardo. 1997. Daily variations of immunoreactive melatonin in the visual system of crayfish. Biol. Cell. 89: 539-543.

Biswas, A. K., M. Seoka, Y. Inoue, K. Takit, and H. Kumai. 2005. Photoperiod influences the growth, food intake, feed efficiency and digestibility of red sea bream Pagrus major. Aquaculture 250: 666-673.

Cullen, M., R. S. Kaufmann, and M. S. Lowery. 2003. Seasonal variation in biochemical indicators of physiological status in Euphausia superba from Port Foster, Deception Island, Antarctica. Deep-Sea Res. II 50: 1787-1798.

Donnelly, J., H. Kawall, S. P. Geiger, and J. J. Torres. 2004. Metabolism of Antarctic micronektonic crustacea across a summer ice-edge bloom: Respiration, composition, and enzymatic activity. Deep-Sea Res. II 51: 2225-2245.

Duinker, A., C. Saout, and Y. M. Paulet. 1999. Effect of photoperiod on conditioning of the great scallop. Aquacult. Int. 7: 449-457.

Fanjul-Moles, M. L., T. Bosques-Tistler, J. Prieto-Sagredo, O. Castañón-Cervantes, and L. Fernández-Rivera-Rio. 1998. Effect of variation in photoperiod and light intensity on 
oxygen consumption, lactate concentration and behavior in crayfish Procambarus clarkii and Procambarus digueti. Comp. Biochem. Physiol. A 119: 263-269.

Gardner, C., And G. B. Maguire. 1998. Effect of photoperiod and light intensity on survival, development and cannibalism of larvae of the Australian giant crab Pseudocarcinus gigas (Lamarck). Aquaculture 165: 51-63.

Hagen, W., G. Kattner, A. Terbrüggen, and E. S. Van Vleet. 2001. Lipid metabolism of the Antarctic krill Euphausia superba and its ecological implications. Mar. Biol. 139: 95-104.

Hamner, W. M., P. P. Hamner, S. W. Strand, and R. W. GILMER. 1983. Behaviour of Antarctic krill Euphausia superba: Chemoreception, feeding, schooling, and molting. Science 220: 433-435.

Hirano, Y., T. Matsuda, and S. Kawagushi. 2003. Breeding Antarctic krill in captivity. Mar. Fresh. Behav. Physiol. 36: 259-269.

Hoang, T., M. Barchiesis, S. Y. Lee, C. P. Keenan, and G. E. Marsden. 2003. Influence of light intensity and photoperiod on moulting and growth of Penaeus merguiensis cultured under laboratory conditions. Aquaculture 216: 343-354.

Huntley, M. E., W. Nordhausen, and M. D. G. Lopez. 1994. Elemental composition, metabolic activity and growth of Antarctic krill Euphausia superba during winter. Mar. Ecol. Prog. Ser. 107: 23-40.

IkedA, T., AND P. Dixon. 1982. Body shrinkage as a possible overwintering mechanism of the Antarctic krill, Euphausia superba Dana. J. Exp. Mar. Biol. Ecol. 62: 143-151.

- AND - 1984. The influence of feeding on the metabolic activity of Antarctic krill (Euphausia superba Dana). Polar Biol. 3: 1-9.

Kawaguchi, K., S. Ishikawa, and O. Matsuda. 1986. The overwintering strategy of Antarctic krill (Euphausia superba Dana) under the coastal fast ice off the Ongul Islands in Lützow-Holm Bay, Antarctica. Mem. Nat. Inst. Polar Res. Spec. Iss. 44: 67-85.

King, R., S. Nicol, P. Cramp, and K. M. Swadling. 2003. Krill maintenance and experimentation at the Australian Antarctic Division. Mar. Fresh. Behav. Physiol. 36: 271-283.

Marschall, H.-P. 1988. The overwintering strategy of Antarctic krill under pack-ice of the Weddell Sea. Polar Biol. 9: 245-250.
Meyer, B., A. Atrinson, B. Blume, and U. Bathmann. 2003. Feeding and energy budgets of larval Antarctic krill Euphausia superba in summer. Mar. Ecol. Prog. Ser. 257: 167-178.

- , R. Saborowski, A. Atkinson, F. Buchholz, and U. BAtHMANN. 2002. Seasonal differences in citrate synthase and digestive activity in larval and postlarval Antarctic krill, Euphausia superba. Mar. Biol. 141: 855-862.

Morris, D. J., AND J. PridDle. 1984. Observations on the feeding and moulting of the Antarctic krill, Euphausia superba Dana, in winter. Br. Antarctic. Surv. Bull. 65: 57-63.

Nicol, S., P. Virtue, R. King, S. R. Davenport, A. F. McGaffin, And P. Nichols. 2004. Condition of Euphausia crystallorophias off East Antarctica in winter in comparison to other seasons. Deep-Sea Res. II 51: 2215-2224.

Otero, M., V. Rossi, A. Baltanas, and P. Menozzi. 1998. Effect of genotype and photoperiod on diapause strategies in Eucypris virens (Jurine, 1820) (Crustacea: Ostracoda). Evolutionary and ecological aspects of crustacean diapause. Adv. Limnol. 52: 229-236.

Quetin, L. B., AND R. M. Ross. 1991. Behavioural and physiological characteristics of the Antarctic krill, Euphausia superba. Am. Zool. 31: 49-63.

Reiter, R. J. 1991. Melatonin: The chemical expression of darkness. Mol. Cell. Endocrinol. 79: C153-C158.

Siegel, V., AND V. Loeb. 1995. Recruitment of Antarctic krill Euphausia superba and possible causes for its variability. Mar. Ecol. Prog. Ser. 123: 45-56.

Southwood, A. L., C. A. Darveau, and D. R. Jones. 2003. Metabolic and cardiovascular adjustments of juvenile green turtles to seasonal changes in temperatures and photoperiod. J. Exp. Biol. 206: 4521-4531.

Tilden, A. R., J. K. Shanahan, Z. S. Khilji, J. G. Owen, T. W. Sterio, and K. T. Thurston. 2003. Melatonin and locomotor activity in the Fiddler Crab Uca pugilator. J. Exp. Zool. A 297: 80-87.

Torres, J. J., J. Donnelly, T. L. Hopkins, T. M. Lancraft, A. V. Aarset, and D. G. Ainley. 1994. Proximate composition and overwintering strategies of Antarctic micronektonic crustacea. Mar. Ecol. Prog. Ser. 113: 221-232.

Vivien-Roels, B., And P. Pévet. 1993. Melatonin: Presence and formation in invertebrates. Experientia 49: 642-647.

Received: 29 May 2006 Accepted: 5 November 2006 Amended: 4 December 2006 